\title{
COMPARATIVE STUDY OF THE PROTECTIVE EFFECT OF ARONIA MELANOCARPA FRUIT JUICE AND QUERCETIN IN A MODEL OF PARACETAMOL-INDUCED HEPATOTOXICITY IN RATS
}

\section{Stefka Valcheva-Kuzmanova}

Department of Preclinical and Clinical Pharmacology, Medical University Prof. Dr. Paraskev Stoyanov, Varna

\section{Corresponding Author:}

Stefka Valcheva-Kuzmanova

Department of Preclinical and Clinical Pharmacology

Medical University

55 Marin Drinov str.

Varna, 9002

Bulgaria

Bulgaria

e-mail:stefkavk@yahoo.com

Received: June 11, 2015

Revision received: August 08, 2015

Accepted: December 01, 2015

\author{
Summary
}

Aronia melanocarpa fruit juice (AMFJ) is very rich in polyphenolic compounds. Quercetin is a naturally occurring flavonoid, one of AMFJ polyphenols. The aim of the present study was to investigate the effect of AMFJ in comparison with quercetin in a model of paracetamolinduced hepatotoxicity in rats. AMFJ at doses of 2.5 and $5.0 \mathrm{ml} / \mathrm{kg}$ and quercetin at doses of 50 and $100 \mathrm{mg} / \mathrm{kg}$ were administered daily orally from day 1 to day 7 to different animal groups. Paracetamol was applied intraperitoneally $(1.0 \mathrm{~g} / \mathrm{kg})$ on day 5 . Blood and liver ware taken for biochemical investigations on day 7. Liver toxicity was estimated by the serum activities of the enzymes aspartate aminotransferase (AST) and alanine aminotransferase (ALT). Oxidative stress was estimated by the levels of thiobarbituric acid reactive substances (TBARS) in liver homogenate and serum. Paracetamol caused a significant elevation of serum AST and ALT, and induced lipid peroxidation as measured by the significant increase of TBARS in serum and liver. In animals pretreated either with AMFJ or quercetin, liver enzyme activities did not differ significantly from the control levels. Both AMFJ and quercetin prevented the elevation of TBARS in the liver at the two applied doses and in the serum only at the higher of the tested doses. In the present model of paracetamol-induced hepatotoxicity, the protective effect of AMFJ was comparable to that of quercetin.

Key words: Aronia melanocarpa fruit juice, quercetin, paracetamol, hepatotoxicity, rats

\section{Introduction}

The liver is a subject to acute and potentially lethal injury by several substances including some drugs such as paracetamol. Paracetamol is a commonly used antipyretic and analgesic which can lead to liver damage if taken in overdose. At therapeutic doses, the drug is converted by conjugation to watersoluble metabolites which are excreted in the urine. In overdose, the normal conjugative pathways of metabolism become saturated. Then excess paracetamol is oxidized via the $\mathrm{P} 450$ system to a toxic metabolite $\mathrm{N}$-acetyl-P-benzoquinoneimine (NAPQI). NAPQI is rapidly conjugated with glutathione to a non-toxic conjugate. When excessive quantities of NAPQI are formed they 
cannot be fully conjugated with glutathione. Under these conditions, NAPQI covalently binds to vital proteins and plasma lipids of hepatocytes. The result is centrilobular liver necrosis and cellular death [1]. The hepatic cell injuries cause the leaking of cellular enzymes into the blood stream and thus can be measured in the serum. The well established effects of a paracetamol overdose on mitochondria include inhibition of mitochondrial respiration and enhanced formation of reactive oxygen species (ROS) and peroxynitrite [2]. The products of lipid peroxidation (thiobarbituric acid reactive substances, TBARS) in paracetamol toxicity serve as a marker of oxidative stress in the tissue [2].

Quercetin is one of the most widely distributed flavonoids. It is one of the components of AMFJ. Quercetin was shown to possess a protective effect against paracetamolinduced liver toxicity which was comparable to the effect of $\mathrm{N}$-acetylcysteine, the antidote approved in paracetamol poisoning $[3,4]$.

Aronia melanocarpa [Michx.] Elliot (black chokeberry) fruits are extremely rich in phenolic compounds: procyanidins, flavonoids (mainly from the subclass of anthocyanins) and phenolic acids (chlorogenic and neochlorogenic) [5]. Our previous studies [6,7], as well as the studies of other authors $[8,9]$ have investigated the antioxidant properties of Aronia juice, Aronia extract or its phenolic constituents using different well established assays. Fresh Aronia berries possess the highest antioxidant capacity among berries and other fruits investigated so far $[8,9]$. A previous study of ours has demonstrated a pronounced protective effect of AMFJ in a model of carbon tetrachloride-induced hepatotoxicity in rats [10]. Up to date, there are no investigations on the effect of AMFJ in a model of paracetamolinduced hepatotoxicity.

The aim of the present study was to investigate the effect of Aronia melanocarpa fruit juice (AMFJ) in comparison with quercetin on liver toxicity and oxidative stress in a model of paracetamol-induced hepatotoxicity in rats.

\section{Materials and Methods}

\section{Experimental animals}

Male Wistar rats (200-250 g) were used in the experiment. The animals were kept under the standard conditions of the animal house with 12- h light-dark cycle (light 700-1900) at a temperature $23-25^{\circ} \mathrm{C}$. They had free access to food and drinking water with the exception of the period of 42 hours before paracetamol administration when all experimental groups were deprived of food. All procedures concerning animal treatment and experimentation were in accordance with the Principles of Laboratory Animal Care (NIH publication № 85-23, revised in 1985), with the European Communities Council Directives 86/609/EEC and the National regulations.

\section{Experimental substances}

Paracetamol (acetaminophen) and quercetin were from Sigma-Aldrich Chemie GmbH (Germany). Standart test kids of BioSystems S.A., Barcelona, Spain were used for the measurement of liver enzyme activities. Tween 80 , dimethyl sulfoxide (DMSO) and all other chemicals for the biochemical analyses were of analytical grade and were obtained from Merck (Germany).

AMFJ was prepared from Aronia melanocarpa fruits which were handpicked, crushed and squeezed. The juice was filtered, pasteurized at $80^{\circ} \mathrm{C}$ for $10 \mathrm{~min}$ and stored at room temperature till the experiment. The contents of phenolic substances in $100 \mathrm{mLAMFJ}$ were: total phenolics, $709.3 \pm 28.1 \mathrm{mg}$ as gallic acid equivalents, determined spectrophotometrically according to the Folin-Ciocalteu procedure [11]; total flavonoids, $189.4 \pm 8.6 \mathrm{mg}$ as catechin equivalents, measured by a colorimetric assay developed by Zhishen et al. [12]; total anthocyanins, $106.8 \pm 6.2 \mathrm{mg}$ as cyanidin-3glucoside equivalents, determined by a $\mathrm{pH}-$ differential spectrophotometry at $\mathrm{pH} 1.0$ and $\mathrm{pH}$ 4.5 [13]; quercetin, $11.8 \mathrm{mg}$, measured by a highperformance liquid chromatography method [14]. The values were the mean of duplicate determinations of three samples.

\section{Experimental procedure}

The animals were randomly divided in five experimental groups each of 10 rats and were treated according to the experimental procedure in Table 1. AMFJ doses were diluted with distilled water to a total volume of $10 \mathrm{ml} / \mathrm{kg}$. Quercetin as a solution in 5\% DMSO was administered at a volume of $10 \mathrm{ml} / \mathrm{kg}$. Paracetamol was applied as a suspension with $2 \%$ Tween 80 at a volume of $4.0 \mathrm{ml} / \mathrm{kg}$. 
Table 1. Experimental procedure

\begin{tabular}{lll}
\hline $\begin{array}{l}\text { Group } \\
(\mathrm{n}=10)\end{array}$ & $\begin{array}{l}\text { Orally by stomach intubation } \\
\text { From day 1 to day 7 }\end{array}$ & $\begin{array}{l}\text { Itraperitoneally } \\
\text { On day 5, 2 hours after the oral treatment }\end{array}$ \\
\hline Control (C) & Distilled water $(10 \mathrm{ml} / \mathrm{kg})$ & $2 \%$ Tween $80(4.0 \mathrm{ml} / \mathrm{kg})$ \\
Paracetamol (P) & Distilled water $(10 \mathrm{ml} / \mathrm{kg})$ & Paracetamol $1.0 \mathrm{~g} / \mathrm{kg}$ \\
$\mathrm{AMFJ}_{2.5}+\mathrm{P}$ & AMFJ $2.5 \mathrm{ml} / \mathrm{kg}$ & Paracetamol $1.0 \mathrm{~g} / \mathrm{kg}$ \\
$\mathrm{AMFJ}_{5}+\mathrm{P}$ & AMFJ $5.0 \mathrm{ml} / \mathrm{kg}$ & Paracetamol $1.0 \mathrm{~g} / \mathrm{kg}$ \\
$\mathrm{Q}_{50}+\mathrm{P}$ & Quercetin $50 \mathrm{ml} / \mathrm{kg}$ & Paracetamol $1.0 \mathrm{~g} / \mathrm{kg}$ \\
$\mathrm{Q}_{100}+\mathrm{P}$ & Quercetin $100 \mathrm{ml} / \mathrm{kg}$ & Paracetamol $1.0 \mathrm{~g} / \mathrm{kg}$ \\
\hline
\end{tabular}

\section{Serum and liver homogenate preparation}

On day 7, 48 hours after paracetamol administration, the animals were anaesthetized with diethyl ether 2 hours after the last treatment with distilled water, AMFJ or quercetin. Blood was collected from the sublingual veins. It was centrifuged at $2000 \mathrm{rpm}$ for $10 \mathrm{~min}$ and serum was obtained for the biochemical analyses.

Samples of liver tissue were homogenized with ice cold Tris/ $\mathrm{HCl}, 50 \mathrm{mM}$, pH 7.4 (1:10). The homogenate was centrifuged (2000 rpm, 10 $\min , 4{ }^{\circ} \mathrm{C}$ ) and the supernatant was used for the biochemical investigations.

\section{Biochemical analyses}

Serum activities of liver enzymes aspartate aminotransferase (AST) and alanine aminotransferase (ALT) were determined spectrophotometrically (Aurius 2021 UV-VIS, Cecil Instruments Ltd, UK) using the standard test kids.

Lipid peroxidation levels were estimated by the thiobarbituric acid (TBA) reaction using the method of Ohkawa et al. [15]. The method measures spectrophotometrically the color produced by the reaction of TBA with lipid peroxides (thiobarbituric acid reactive substances, TBARS) at $532 \mathrm{~nm}$. Malondialdehyde, the major reactive aldehyde resulting from the peroxidation of biological membrane polyunsaturated fatty acids, was used as a standard.

\section{Statistical analysis}

Data were analysed statistically by one-way analysis of variance (ANOVA) followed by Dunnett's multiple comparison post test. A value of $p<0.05$ was considered as statistically significant. Data are expressed as mean \pm SEM. GraphPad Prism statistical software was used.

\section{Results}

\section{Liver enzymes}

The liver enzyme activities are presented on Figure 1. The administration of paracetamol caused a significant elevation of serum AST $(p<0.01$ vs. Control) and ALT $(p<0.05$ vs. Control). AMFJ as well as quercetin at the tested doses prevented the increase of these enzyme activities. Thus, in rats belonging to groups $\mathrm{AMFJ}_{2.5}+\mathrm{P}, \mathrm{AMFJ}_{5}+\mathrm{P}, \mathrm{Q}_{50}+\mathrm{P}$ and $\mathrm{Q}_{100}+\mathrm{P}$ the levels of AST and ALT did not differ significantly from the control value (Figure 1).

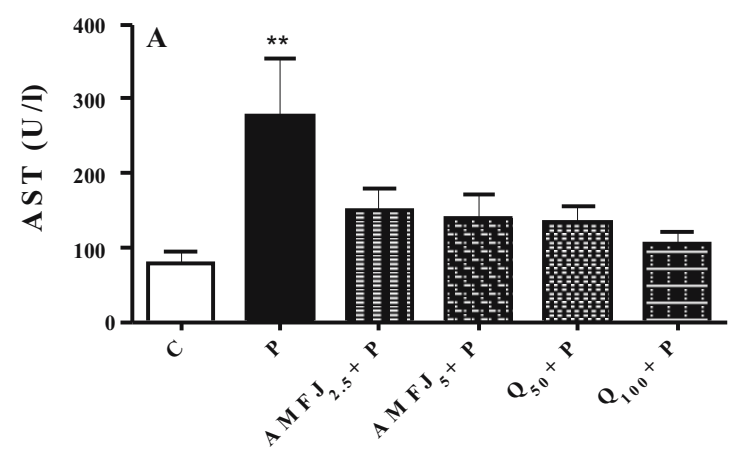

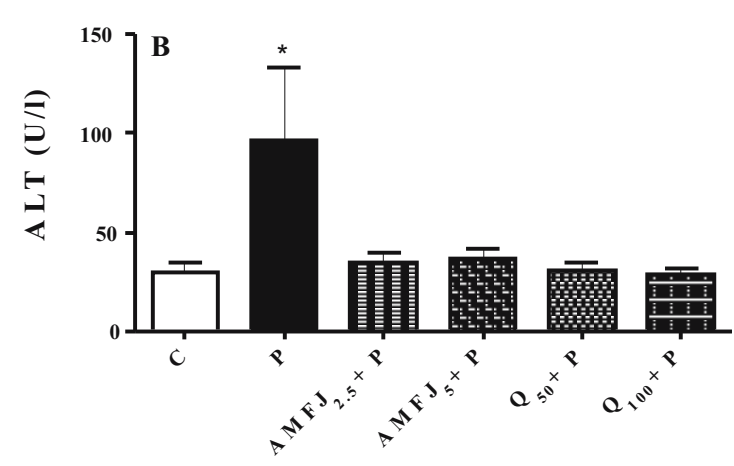

Figure 1. Effect of Aronia melanocarpa fruit juice (AMFJ) applied at doses of 2.5 and $5 \mathrm{ml} / \mathrm{kg}$ and quercetin (Q) at doses of 50 and $100 \mathrm{mg} / \mathrm{kg}$ on the activities of AST (panel A) and ALT (panel B) in a model of paracetamol $(\mathrm{P})$-induced hepatotoxicity in rats. Values are mean $\pm \mathrm{SEM} ; \mathrm{n}=10 ;{ }^{*} \mathrm{p}<0.05,{ }^{* *} \mathrm{p}<0.01$ vs. Control (C) 


\section{Thiobarbituric acid reactive substances}

Paracetamol induced lipid peroxidation as measured by the significant increase of TBARS in the liver $(\mathrm{p}<0.05$ vs. Control) and serum $(\mathrm{p}<0.01$ vs. Control) (Figure 2). As is obvious from Figure 2, the TBARS in the livers of rats belonging to groups $\mathrm{AMFJ}_{2.5}+\mathrm{P}, \mathrm{AMFJ}_{5}+\mathrm{P}, \mathrm{Q}_{50}+$ $\mathrm{P}$ and $\mathrm{Q}_{100}+\mathrm{P}$ did not differ significantly from the control level. In rat serum, there was a dose-

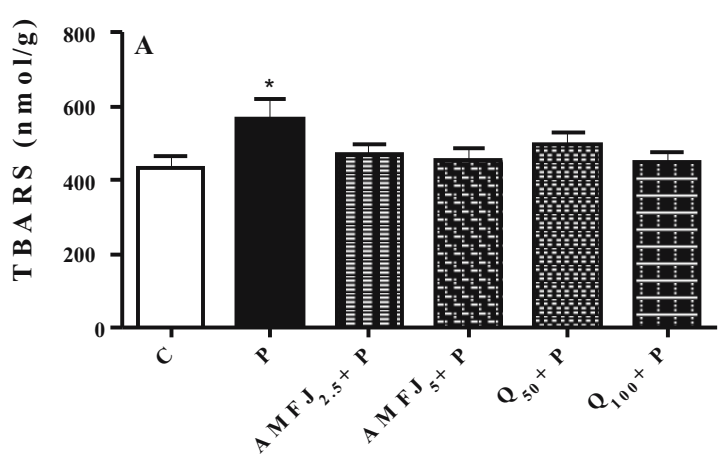

dependent effect of AMFJ and quercetin on the concentration of TBARS. In rats treated with AMFJ at the dose of $2.5 \mathrm{ml} / \mathrm{kg}$ as well as with quercetin at the dose of $50 \mathrm{mg} / \mathrm{kg}$ the serum concentrations of TBARS were significantly higher $(p<0.05)$ than the control level. In rats treated with the higher doses of AMFJ $(5 \mathrm{ml} / \mathrm{kg})$ and quercetin $(100 \mathrm{mg} / \mathrm{kg})$ the concentrations of TBARS in serum were not significantly different from the control value (Figure 2).

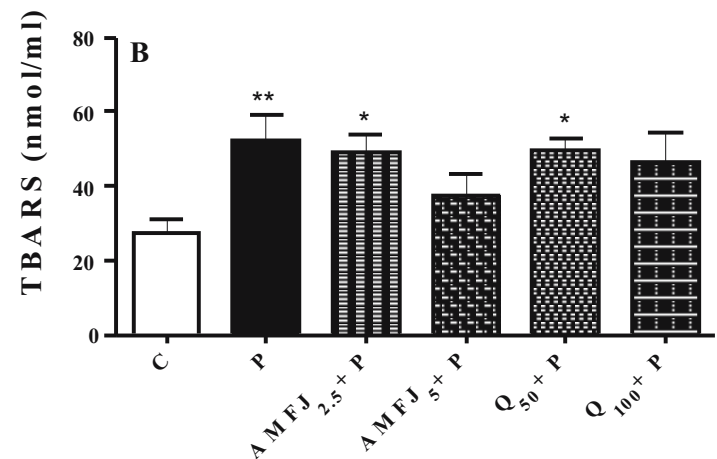

Figure 2. Effect of Aronia melanocarpa fruit juice (AMFJ) applied at doses of 2.5 and $5 \mathrm{ml} / \mathrm{kg}$ and quercetin (Q) at doses of 50 and $100 \mathrm{mg} / \mathrm{kg}$ on the concentration of TBARS in liver (panel A) and serum (panel B) in a model of paracetamol (P)-induced hepatotoxicity in rats. Values are mean $\pm \mathrm{SEM} ; \mathrm{n}=10 ;{ }^{*} \mathrm{p}<0.05, * * \mathrm{p}<0.01$ vs. Control (C)

\section{Discussion}

The paracetamol-induced toxicity model is commonly used to study the potential hepatoprotective activity of compounds [16]. In the present investigation, the toxic dose of paracetamol $(1.0 \mathrm{~g} / \mathrm{kg})$ resulted in a significant elevation of liver enzymes as markers of the liver damage and TBARS as markers of oxidative stress. The paracetamol reactive metabolite NAPQI as described previously is responsible for the development of the hepatotoxicity. Literature data suggest that the NAPQI binds to the mitochondrial proteins and triggers a mitochondrial oxidant stress [16] which finally causes activation of apoptosis [17] and cellular necrosis [18]. Therefore, it is hypothesized that compounds with free radical scavenging and/or antioxidant activities could be protective against the paracetamol-induced liver toxicity. CYP2E1 and CYP1A2 are the major isoenzymes of paracetamol bioactivation [19]. CYP2E1 is an important isoform that participates in the generation of ROS such as superoxide and hydrogen peroxide. ROS may mediate the toxic effects of xenobiotics. Thus, in CYP2E1- knockout mice paracetamol has been found to be considerably less toxic than in wild-type animals [20].

Phytochemical screening of AMFJ has demonstrated the presence of polyphenol substances which have been reported to exert antioxidant, anti-inflammatory and hepatoprotective activities. In the present study, AMFJ at the two applied doses decreased the biochemical indices of liver toxicity and oxidative stress in rats. At least two mechanisms might account for that effect of AMFJ. One of them is the extremely high antioxidant activity of the juice and the capacity to scavenge ROS reviewed by Denev et al. [5]. The other mechanism might be the effect of the juice on the activity of liver enzymes engaged in the metabolism of paracetamol. The study of KrajkaKuźniak et al. [21] showed that the forced feeding with chokeberry juice alone decreased the activities of cytochrome CYP1A1 and CYP $1 \mathrm{~A} 2$, and the pretreatment with the juice further reduced the activity of CYP2E1 which was decreased by N-nitrosodiethylamine. These data suggest that AMFJ might inhibit the generation of the toxic metabolite of paracetamol NAPQI. 
Quercetin is a flavonoid that has been very intensively studied. In recent years, there are investigations with quercetin in models of paracetamol-induced liver toxicity, which show a very good protective effect of the flavonoid $[3,4$, 22]. In these studies, the hepatoprotective effect of quercetin was accompanied by a decrease in oxidative stress and an increase in the antioxidant protection of the animals. Guzy et al. [22] investigated the effect of quercetin on paracetamol-induced mitochondrial dysfunction and found that paracetamol caused significant changes in mitochodrial respiratory chain and mitochondrial ATPase while quercetin counteracted these effects due to its antioxidant potential.

The doses of 2.5 and $5 \mathrm{ml} / \mathrm{kg}$ of AMFJ contained respectively about 17.5 and $35 \mathrm{mg} / \mathrm{kg}$ of total polyphenols. In the present experiment, the effects of these AMFJ doses were comparable to those of quercetin at doses of 50 and 100 $\mathrm{mg} / \mathrm{kg}$. Based on previous data [23, 24], the effects of AMFJ possibly involve the synergistic interaction between flavonoids and other polyphenolic substances in the juice.

\section{Conclusions}

This study showed that AMFJ had a protective effect against paracetamol-induced hepatotoxicity in rats. The effect was comparable to that of the flavonoid quercetin and was probably due to antioxidant activity and inhibition of enzymes participating in the generation of the toxic paracetamol metabolite.

\section{References}

1. McConnachie LA, Mohar I, Hudson FN, Ware CB, Ladiges WC, Fernandez $\mathrm{C}$ et.al. Glutamate cysteine ligase modifier subunit deficiency and gender as determinants of acetaminophen-induced hepatotoxicity in mice. Toxicol Sci. 2007;99(2):628-36.

2. Jaeschke H, Knight TR, Bajt ML. The role of oxidant stress and reactive nitrogen species in acetaminophen hepatotoxicity. Toxicol Lett. 2003;144(3):279-88.

3. Yousef MI, Omar SA, El-Guendi MI, Abdelmegid LA. Potential protective effects of quercetin and curcumin on paracetamol-induced histological changes, oxidative stress, impaired liver and kidney functions and haematotoxicity in rat. Food Chem Toxicol. 2010;48(11):3246-61.
4. Singh S, Singh SK, Kumar M, Chandra K, Singh R. Ameliorative potential of quercetin against paracetamol-induced oxidative stress in mice blood. Toxicol Int. 2011;18(2):140-5.

5. Denev PN, Kratchanov CG, Ciz M, Lojek A, Kratchanova MG. Bioavailability and antioxidant activity of black chokeberry (Aronia melanocarpa) polyphenols: in vitro and in vivo evidences and possible mechanisms of action. A review. Comp Rev Food Sci Food Safety. 2012;11(5):471-89.

6. Valcheva-Kuzmanova S, Gadjeva V, Ivanova D, Belcheva A. Antioxidant activity of Aronia melanocarpa fruit juice in vitro. Acta Aliment. 2007;36(4):425-8.

7. Valcheva-Kuzmanova S, Blagović B, Valić S. Electron spin resonance measurement of radical scavenging activity of Aronia melanocarpa fruit juice. Pharmacog Mag. 2012;8(30):171-4.

8. Zheng W, Wang SY. Oxygen radical absorbing capacity of phenolics in blueberries, cranberries, chokeberries, and lingonberries. J Agric Food Chem. 2003;51(2):502-9.

9. $\mathrm{Wu} \mathrm{XL}, \mathrm{Gu} \mathrm{LW}$, Prior RL, McKay S. Characterization of anthocyanins and proanthocyanidins in some cultivars of Ribes, Aronia, and Sambucus and their antioxidant capacity. J Agric Food Chem. 2004;52(26):784656.

10. Valcheva-Kuzmanova S, Borisova P, Galunska B, Krasnaliev I, Belcheva A. Hepatoprotective effect of the natural fruit juice from Aronia melanocarpa on carbon tetrachloride-induced acute liver damage in rats. Exp Toxicol Pathol. 2004;56(3):195-201.

11. Singleton VL, Rossi JA. Colorimetry of total phenolics with phosphomolybdic phosphotungstic acid reagents. Am J Emol Viticult. 1965;16(3):144-58.

12. Zhishen J, Mengcheng T, Jianming W. The determination of flavonoid contents in mulberry and their scavenging effects on superoxide radicals. Food Chem. 1999;64(4):555-9.

13. Guisti MM, Rodrigues-Saona LE, Wrolstad RE. Molar absorptivity and color characteristics of acylated and non-acylated pelargonidin-based anthocyanins. J Agric Food Chem. 1999;47:46317.

14. Hertog MGL, Hollman PCH, Vanema DP. Optimization of a quantitative HPLC determination of potentially anticarcinogenic flavonoids in vegetables and fruits. J Agric Food Chem. 1992;40(9):1591-8.

15. Ohkawa H, Ohishi N, Iagi K. Assay for lipid peroxides in animal tissues by thiobarbituric acid reaction. Anal Biochem. 1979;95(2):351-8.

16. Jaeschke H, Williams CD, McGill MR, Xie Y, Ramachandran A. Models of drug-induced liver injury for evaluation of phytotherapeutics and other natural products. Food Chem Toxicol. 
2013;55:279-89.

17. Nakagawa H, Maeda S, Hikiba Y, Ohmae T, Shibata W, Yanai A, et al. Deletion of apoptosis signal-regulating kinase 1 attenuates acetaminophen-induced liver injury by inhibiting c-Jun N-terminal kinase activation. Gastroenterology. 2008;135(4):1311-21.

18. Bajt ML, Farhood A, Lemasters JJ, Jaeschke H. Mitochondrial bax translocation accelerates DNA fragmentation and cell necrosis in a murine model of acetaminophen hepatotoxicity. J Pharmacol Exp Ther. 2008;324(1):8-14.

19. Kalsi SS, Wood DM, Waring WS, Dargan PI. Does cytochrome P450 liver isoenzyme induction increase the risk of liver toxicity after paracetamol overdose? OA Emergency Medicine. 2011;3:6976.

20. Shayiq RM, Roberts DW, Rothstein K, Snawder J E, Benson W, Ma X, et al. Repeat exposure to incremental doses of acetaminophen provides protection against acetaminophen-induced lethality in mice: An explanation for high acetaminophen dosage in humans without hepatic injury. Hepatology. 1999;29(2):451-63.
21. Krajka-Kuźniak V, Szaefer H, Ignatowicz E, Adamska T, Oszmiański J, Baer-Dubowska W. Effect of Chokeberry (Aronia melanocarpa) juice on the metabolic activation and detoxication of carcinogenic N-nitrosodiethylamine in rat liver. J Agric Food Chem. 2009;57(11):5071-7.

22. Guzy J, Chovanová Z, Mareková M, Chavková Z, Tomeèková V, Možišová G, et al. Effect of quercetin on paracetamol-induced rat liver mitochondrial dysfunction. Biologia Bratislava. 2004;59(3):399-403.

23. Baranova VS, Rusina IF, Guseva DA, Prozorovskaia NN, Ipatova OM, Kasaikina OT. The antiradical activity of plant extracts and healthful preventive combinations of these exrtacts with the phospholipid complex. Biomed Khim. 2012;58(6):712-26.

24. Valcheva-Kuzmanova S, Stavreva G, Dancheva V, Terziev L, Shopova V. Effect of Aronia melanocarpa fruit juice on the activity of antioxidant Enzymes in a rat model of amiodarone-induced pneumotoxicity. J Biomed Clin Res. 2012;5(2):97-103. 